\title{
○equetáa
}

\section{Divulgação científica nos arquivos do Brasil: representação arquivística na construção da memória e identidade}

\author{
Evelyn Goyannes Dill Orrico \\ Doutora; Universidade Federal do Estado do Rio de Janeiro, Rio de Janeiro, RJ, Brasil \\ evelynorrico@unirio.br \\ Eliezer Pires da Silva \\ Doutor; Universidade Federal do Estado do Rio de Janeiro, Rio de Janeiro, Brasil \\ eliezerpires@gmail.com
}

\begin{abstract}
Resumo: Objetivar a divulgação dos acervos arquivísticos para um público amplo é tarefa estimulante porque, tradicionalmente, esse público não visita os arquivos.O pressuposto de que é função social do arquivo ampliar a utilização de seus acervos e o número de seus usuários é o que norteia este estudo sobre as condições do acesso aos documentos de arquivo por parte da população. Assim agindo, o arquivo permite a efetivação da plena cidadania. A dimensão divulgadora faz com que essas instituições consigam atingir um público cada vez maior para utilizar seus acervos, aumentando o número de seus usuários. $\mathrm{O}$ objetivo desta proposta é tematizar a perspectiva de ampliação do acesso aos documentos custodiados nos arquivos, considerando a existência de instituições que anunciam ter essa finalidade para os acervos que organizam e preservam. A abordagem metodológica é exploratória e utilizou a revisão de literatura sobre categorias conceituais relacionadas com divulgação de acervos arquivísticos e construção de memórias. Os resultados são: ainda há uma identificação precária entre os arquivos públicos e a maior parte da população; nota-se a insuficiência de estratégias elaboradas pelas entidades custodiadoras sobre seus acervos arquivísticos de modo a atingir um público amplo que comumente não visitaria os arquivos. Esta investigação não só amplia o conhecimento sobre os arquivos como recurso informacional para o cidadão, mas principalmente propicia a produção de conhecimento sobre um tema fundamental para a emergência de novas discussões no espaço acadêmico envolvendo diversos atores sociais: a representação do conhecimento arquivístico para a população leiga.
\end{abstract}

Palavras-chave: Divulgação científica. Arquivos. Memória e discurso. 


\section{Introdução}

Desde os anos de 1970, a institucionalização do campo arquivístico brasileiro passou por importantes etapas de desenvolvimento. Concretamente, a configuração ainda é de uma precária efetividade do acesso público aos acervos custodiados pelas instituições arquivísticas. No entanto, podem-se constatar avanços na percepção sobre o uso social dos arquivos no país, tendo em vista a crescente demanda social pela transparência do Estado, o direito à informação e o direito à memória.

O arcabouço teórico-metodológico que sustenta esta proposta de pesquisa encontra suas referências fundamentais nos campos da Arquivologia e da Ciência da Informação, como vem sendo construído em projetos desenvolvidos no âmbito do Programa de Pós-Graduação em Memória Social.

Dois pressupostos gerais norteiam a execução desta proposta: o valor da informação arquivística não reside em si mesmo, ele se potencializa com a circulação e uso dessa informação mediante instrumentos que favoreçam sua significação para o cidadão gerar conhecimento; os arquivos precisam ser instituições mais populares do que são, isso para que mais pessoas possam se beneficiar de seus acervos para aumentar o conhecimento, criando uma sociedade gradativamente mais instruída, mais plural e mais democrática.

Nessa linha de pesquisa, já se tem trabalhado sobre o fato de que, após o recolhimento dos registros à custódia de uma instituição arquivística, é realizado o tratamento técnico de classificação e de descrição dos acervos, com a representação e o controle intelectual do conteúdo dos documentos nos instrumentos de pesquisa que serão utilizados pelo usuário na busca por informação . As instituições arquivísticas têm a função social de garantir acesso aos documentos de sua custódia por meio de instrumentos que representam o conteúdo desses registros, efetivando a transferência de informação nos arquivos como um processo que vai do armazenamento do documento até a divulgação de seus conteúdos, nesse sentido, os instrumentos de pesquisa concretizam essa finalidade. 
Assim, observa-se que, em princípio, não é o documento em si que é oferecido, mas uma representação elaborada pela equipe profissional da instituição sobre o conteúdo dos documentos. Adota-se aqui a compreensão de que essa atividade é uma mediação entre o documento e o usuário, e tal contexto de acesso é a problematização central nesta pesquisa.

Ao considerar a construção dos instrumentos de pesquisa que indexam os documentos de arquivo custodiados, entende-se, ainda, que tais instrumentos podem tanto colocar em evidência, quanto fazer desaparecer documentos de arquivo diante dos usuários. Essa dupla possibilidade perpassa a discussão teórica do acesso aos acervos arquivísticos. As instituições arquivísticas têm a função social de garantir acesso aos documentos de sua custódia por meio de instrumentos que representam o conteúdo desses registros, efetivando a transferência de informação nos arquivos como um processo que vai do armazenamento do documento até a divulgação de seus conteúdos, nesse sentido, os instrumentos de pesquisa concretizam essa finalidade.

Faz parte dos pressupostos teóricos desta pesquisa compreender as condições do exercício do direito à informação e suas relações com o acesso aos arquivos como manifestação de cidadania, para além da liberdade de expressão. Desse modo, o acesso aos documentos de arquivo envolve conhecer práticas e discursos dos quais resultam os arquivos, que são dotadas de uma lógica de controle, governo e gestão. Os arquivos são uma escrita que expressa um saber sobre o funcionamento das instituições e, nesse sentido, constroem a narrativa institucional (NESMITH, 2002).

Para isto, torna-se fundamental investigar sobre os instrumentos de pesquisa utilizados pelos usuários nos arquivos, não somente concernente a atividades do trabalho historiográfico, mas principalmente como recurso importante para o cidadão na construção de sua identidade e cidadania. Isso significa dizer, no sentido mais amplo, que se acredita na concretização do direito à informação por parte do cidadão como um caminho de transparência do Estado à sociedade civil, capaz de subsidiar a participação política como dimensão básica da cidadania e minimização de desigualdades sociais (BAK; HILL, 2015). 
Este artigo é parte inicial de uma pesquisa que analisa as estratégias de promoção do acesso aos acervos arquivísticos, observando alcances e limites das experiências realizadas no contexto brasileiro dos arquivos públicos estaduais, considerando-se as demandas atuais dos cenários tecnológicos e informacionais e seu percurso histórico na última década, em cujo escopo levantam-se as seguintes questões:

a) que aspectos caracterizam, no Brasil, a construção dos instrumentos de representação da informação arquivística que são disponibilizados pelas instituições arquivísticas aos seus usuários?;

b) quais elementos teórico-conceituais sustentam as configurações de uso social dos arquivos no país?;

c) quais as características que marcam as ações e discursos de divulgação dos acervos arquivísticos no contexto brasileiro?;

d) quais as possibilidades teóricas e metodológicas de construção de novos modelos de representação da informação arquivística com ênfase nos usos para a construção de memória e identidade de vários grupos sociais?;

e) quais seriam os possíveis pontos de convergência e divergência entre as experiências das instituições arquivísticas brasileiras nas suas iniciativas de ampliação do acesso público aos acervos arquivísticos?;

f) como os discursos de divulgação dos acervos arquivísticos no Brasil contribuem para a construção de representações identitárias e de memórias da sociedade em geral?

Este artigo, como fruto inicial dessa proposta, apresenta os primeiros resultados da pesquisa, mais especificamente, uma articulação teórico-conceitual envolvendo relações entre memória, patrimônio e discurso no horizonte do fenômeno arquivístico, passando por uma caracterização problematizada de um domínio de divulgação científica nos arquivos e seus instrumentos. 


\section{Relações conceituais entre divulgação científica e memória}

$\mathrm{O}$ aporte teórico deste projeto calca-se naquele que tem sustentado projetos anteriores que vimos desenvolvendo no campo do discurso da construção de memória e identidade. A sustentação teórica evidencia a coerência e a densidade com que são tratadas as questões aqui apresentadas e, em uma dimensão interdisciplinar, engloba aportes teóricos sobre patrimônio e memória que devem ser estudados por uma vertente linguístico-discursivo-informacional, como será visto a seguir.

Em primeiro lugar, considera-se a vertente interdisciplinar do projeto, na medida em que emergem novas perspectivas teórico-conceituais, o que possibilita uma nova atitude de se fazer sujeito no mundo. Essa postura demanda novas formas de pesquisa que permitam, segundo Japiassu (1976, p. 213), rever e reformular as relações entre as ciências humanas e naturais.

A interdisciplinaridade respalda as tendências contemporâneas da Ciência da Informação ao indicar que novas tradições começam a se desenvolver em conexão com problemas atuais de comunicação, inclusive as de trabalho, em que, por exemplo, pesquisadores encontram-se face-a-face com pessoas leigas reais e têm de compreender que, de nenhum modo, eles são "homens de informação" estáticos (WERSIG, 1993, p. 230). Essa postura nas pesquisas da área da Ciência da Informação faz com que, do ponto de vista linguístico, as correntes que têm como pressuposto teórico a inter-relação dos falantes, bem como consideram que as situações de comunicação devem ser utilizadas para estudos no campo da recuperação da informação, sejam as mais adequadas para serem aqui incorporadas.

Em vista dessa relação com a linguagem, vemos que a mediação merece atenção especial, sobretudo nas situações de divulgação. Nas relações entre a Ciência da Informação e a Arquivologia, podem ser observadas contribuições das correntes teóricas de organização do conhecimento (SILVA; ORRICO, 2013). 
Em segundo lugar, pautar a correlação entre Patrimônio e Memória no âmbito das representações discursivo-informacionais. Segundo Gonçalves (2003), a categoria de pensamento - patrimônio - é extremamente importante para a vida social e mental de qualquer coletividade humana, tendo em vista que todo grupamento humano realiza alguma atividade de colecionamento com o objetivo de delimitar um domínio subjetivo, no intuito de demarcar sua identidade em oposição ao "outro". Nesse artigo, o autor afirma que "[...] a categoria patrimônio, em suas variadas representações, parece confundir-se com as diversas formas de autoconsciência cultural [...]" (GONÇALVES, 2003, p. 29). Nosso pressuposto aqui é considerar que as manifestações sociais, que exteriorizam formas de autoconsciência cultural, também sejam manifestadas via discurso. Os discursos estabelecem relação entre a transmissão cultural e suas representações e esse processo constitui memória, conforme concepção de Halbwachs (1997). Assmann (2011) afirma, ainda, que a memória também exerce pressão sobre o presente, a partir das “[...] reivindicações e obrigações rivalizantes [...]" (ASSMANN, 2011, p. 20). Nesse sentido, refletir mais profundamente sobre as formas de divulgação de acervos arquivísticos é permitir que a população se inteire de processos institucionais de diversas naturezas, construindo assim um universo simbólico comum aos indivíduos de um determinado grupo social.

Halbwachs (1997) estabelece a relação entre memória individual e memória coletiva, mostrando que nossas lembranças são coletivas; recordamos em função do(s) outro(s), mesmo quando se trata de eventos aos quais presenciamos, sem nenhuma outra testemunha. Segundo ele, isso ocorre porque nunca estaríamos sozinhos, pois sempre "carregamos conosco" uma quantidade de pessoas que não se misturam.

Tal consideração traz consequências importantes à nossa investigação. É possível pensar o discurso - em sentido lato - como substrato a um trabalho de rememoração do passado ou, também, como um elemento estruturador de memória e constituidor do patrimônio? Halbwachs (1997) estabelece que, para o processo de lembrança, testemunhas materiais - pessoas presentes ao evento que o sujeito presenciou - não são necessárias. Esse posicionamento leva à hipótese 
da existência de uma memória-diálogo (NAMER, 1987), cuja noção reside: na origem social de nossa necessidade de lembrar: lembrar em função de perguntas/situações que nos são colocadas (por nós mesmos ou por terceiros); na relação de exterioridade entre a lembrança e o objeto lembrado: daí o trabalho intelectual de reconstruir a memória com a linguagem.

Ao adotarmos essa concepção de Namer (1987), inserimos os aspectos informacionais nesse arcabouço, tendo em vista que, se há interação social, há trocas de representação via linguagem. Mais uma vez, salientamos a importância de refletir sobre as práticas de acesso aos acervos arquivísticos, porque tal flexibilização de acesso permite à população em geral apoderar-se de sua própria identidade e memória.

A relevância dos estudos que têm a memória como foco é potencializada pelo que Candau (1996), aproximando-se de Huyssen (2000), chama de compulsão memorial que afeta as sociedades. Por esta compulsão, podemos entender, também, um medo do esquecimento, que se relaciona à importância da memória para a manutenção do sujeito social. Pensar nesse sujeito é lembrar de Todorov (1998), para quem a conquista das terras e dos homens passa pela conquista da informação e da comunicação.

Aqui, pensamos na relação entre informação e comunicação, já que consideramos a divulgação dos acervos arquivísticos processos comunicativos in essentia. Passemos, em terceiro lugar, a discutir a concepção de discurso utilizada neste projeto. Não pretendemos inaugurar uma nova concepção ou delimitação do discurso - algo que parece, primeiramente, uma tarefa impossível -, mas sim trazer, para um dado enquadramento teórico, o entrelaçamento da produção discursivo-informacional como evidenciadora e constituidora de memória e identidade, construída na dinâmica das tecnologias de informação e de comunicação da ciência.

Falar em discurso, de algum modo, demanda pensar em perpetuação. A perspectiva que nos move é a de que o discurso se constitui de algo que existia antes mesmo de ser enunciado e, ao mesmo tempo, poderíamos perpetuar algo mesmo depois de não estarmos mais presentes neste mundo. A linguagem é uma das principais faculdades humanas que nos permite perpetuar. 
Essa concepção nos remete a Pêcheux (1999), fundador da Escola Francesa de Análise do Discurso, autor que incorpora a memória em sua concepção de discurso. Ele define a memória como sendo entendida nos “[...] sentidos entrecruzados da memória mítica, da memória social inscrita em práticas, e da memória construída do historiador [...]" (PÊCHEUX, 1999, p. 50)

Refinando essa articulação entre memória e discurso, merece destaque o trabalho de J. J. Courtine (1981) intitulado Analyse du discours politique (le discours communiste adresse aux chrétiens), no qual tal articulação é estabelecida na análise de um corpus constituído pelos discursos dirigidos aos cristãos pelo Partido Comunista Francês durante o período de 1936 a 1976. Nesse trabalho, o autor estabelece um conceito de extrema importância: o de memória discursiva, no qual a define como a existência histórica do enunciado no seio de práticas discursivas reguladas por aparelhos ideológicos. Em que pese esta noção ter sido construída a partir da análise de textos explicitamente políticos, ela é adequada para sustentar questões ideológicas que envolvem a memória que se quer construir na e para a sociedade. Isso nos remete a refletir tanto sobre as práticas discursivas que permitem adentrar os acervos, quanto as que permitem escondê-los e tornar inacessíveis os documentos custodiados.

Indo um pouco mais longe no tempo, muitos estudos que hoje trabalham na confluência da língua com o social creditam a Bakhtin as primeiras teorizações acerca da interação verbal e das relações entre linguagem, sociedade e história.

Verificamos que Bakhtin (2002), no final da terceira década do século $\mathrm{XX}$, afirma que a língua é utilizada pelo locutor para suas necessidades enunciativas concretas, deixando, de certa forma, a conformidade à norma em segundo plano, já que é a forma de utilização e as significações advindas do uso em contextos específicos que importam.

Efetivamente, o pensador russo concebe a língua como se oferecendo aos locutores em momentos de enunciação - concretização do sistema em situações de fala - que implicam "sempre um contexto ideológico preciso". 
importantes ou triviais, agradáveis ou desagradáveis, etc. A palavra é sempre carregada de um conteúdo ou de um sentido ideológico ou vivencial [...] (BAKHTIN, 2002, p. 95).

Essa afirmação de Bakhtin (2002) dialoga com afirmações de Pêcheux (1999), que viria nos advertir, anos mais tarde, que o materialista e o idealista, o revolucionário e o reacionário têm à disposição para seu uso o mesmo sistema de língua, no entanto, não se pode dizer que eles tenham o mesmo discurso.

Ao pautarmos a discussão sobre o discurso na linha de pesquisa que vimos trilhando e da qual este artigo é decorrente, o fazemos tendo em vista que a compreensão desses estudos sobre a linguagem mostra-se mais adequada quando se quer observar a expressividade humana, já que ela pode servir “[...] de índices mais ou menos duradouros dos processos subjetivos de seus produtores [...]" (BERGER; LUCKMANN, 1985, p. 53).

O discurso é, então, uma construção levada a efeito por sujeitos envolvidos em um determinado contexto sócio-político-ideológico, e as relações de força nele engendradas estão contingenciadas pelo momento sócio-históricopragmático em que ocorrem. Por isso, não podemos desconsiderar as relações interdisciplinares em que se organizam os atuais processos de difusão da ciência e, sobretudo, na interface que estabelece com a sociedade no âmbito dos movimentos sociais.

Por fim, mas não menos importante, vamos delimitar os conceitos de informação e alguns outros que a ele se correlacionam, para evidenciar que nossos projetos contribuem para o reforço do plano teórico-conceitual da área da Ciência da Informação.

O conceito de informação admite uma longa lista de definições. Tal lista abrange desde uma conceituação estritamente cognitivista (BELKIN; ROBERTSON, 1976), na qual informação provoca alteração de estruturas cognitivas, até uma concepção na qual Informação só existe como tal se uma relação de significado é estabelecida por intermédio de um atributo de valor Relevância (SARACEVIC, 1970).

O que consideramos importante destacar é que deve haver uma relação harmoniosa entre as mudanças no repertório cognitivo de um indivíduo, a partir de uma atribuição de valor - relevância - estabelecida pelo próprio indivíduo 
em momento tempo-espacial definido, e a produção de conhecimento. Dizemos isso apoiados no que diz Dahlberg (1978), para quem tanto informação é conhecimento em ação quanto conhecimento é informação organizada e digerida. O que denominamos de relação harmoniosa, portanto, é a alteração de repertório cognitivo, no momento em que o conhecimento é gerado, regida por uma atribuição de valor que, por sua vez, é condicionada pelas situações espaçotemporais em que acontecem (ORRICO, 2001).

Em última instância, o que se admite como informação refere-se a qualquer registro - ou inscrição - seja linguístico-textual, imagético, ou sonoro - que provoca alteração nas estruturas cognitivas de um indivíduo, a partir da compreensão da explicitação semântico-sintática de tais registros - ou inscrições -, e satisfaz o interesse daquele que o procura ou recebe, diminuindo a entropia.

Ressalte-se que as alterações cognitivas decorrem de uma capacidade humana, mas a produção de conhecimento delas decorrente é, em grande parte, fruto das condições de interlocução sócio-históricas entre os indivíduos. Consideramos haver, portanto, um entrelaçamento entre as alterações cognitivas e a situação de interlocução em que elas ocorrem, que condiciona a diretriz de conteúdo que, por sua vez, é condicionada pelo papel que o indivíduo exerce em determinado contexto sócio-espacial e em determinado período de tempo histórico.

A proposta teórica que trazemos apresenta um aporte que congrega a preocupação de estabelecer as bases do elo semântico do enunciado, mas leva em consideração a situação contextual em que esse enunciado é produzido.

Aqui, inserem-se as questões relativas à esfera de significação, dentre elas, a informação arquivística, configurando um processo de comunicação que se apoia em práticas estabelecidas num ambiente de ação comunicativa específica que permite circular uma referência com validade, e que tem a ver com a ideia de testemunho encerrado num arquivo. Como vimos, esse aporte teórico nos permitirá abordar os aspectos discursivo-informacionais de uma instituição de memória, os arquivos. 


\section{Representação da informação arquivística na construção da memória}

As possibilidades de compreensão da mediação que se realiza entre o usuário e os acervos arquivísticos requerem a articulação teórica dos conceitos de descrição arquivística e de instrumentos de pesquisa.

A descrição arquivística é o processo em que o arquivista cria representações de um determinado acervo arquivístico, apresentando seu contexto e conteúdo (OLIVEIRA, 2010). É uma atividade intelectual que demanda competências de interpretação de texto, conhecimento histórico e habilidade para redigir descrições dos acervos. O objetivo é o controle dos documentos arquivísticos, tendo em vista a promoção do acesso (SILVA; ORRICO, 2013).

Nas origens da descrição arquivística, essa prática objetivava apenas o controle do acervo, todavia, desde o começo do século XX, a finalidade desse procedimento ter-se-ia ampliado não apenas para prestar conta dos acervos custodiados, mas também para prover o acesso público. "Portanto, o resultado da descrição não é outro que a preservação de significado, o exercício de controle, e a provisão de acesso [...]" (LEÃO, 2006, p. 21).

As definições de descrição arquivística são classificadas entre a tendência de entendê-la como produto, instrumentos resultantes da atividade de descrever, e como processo, ação de representar o conteúdo de acervos arquivísticos.

Esta concepção da descrição arquivística, como um processo para se estabelecer controle intelectual e físico sobre os acervos, é uma concepção bastante focada na elaboração de um produto: os instrumentos de pesquisa. Entretanto, vale observar que ela parece operar com duas categorias distintas de "produto": aqueles que promovem o controle intelectual e os que promovem o controle físico (LEÃO, 2006, p. 29).

Ao discutir o movimento de normalização arquivística, a partir dos anos de 1980, e o surgimento dos primeiros instrumentos de padronização da descrição, associados às novas tecnologias, a autora assinala a referência biblioteconômica subjacente às obras que fundamentaram essas normas e observa que "[...] causa estranheza que um código de catalogação 
biblioteconômico tenha sido a principal referência a fundamentar o desenvolvimento de uma norma de descrição arquivística.” (LEÃO, 2006, p. 45).

Para Júnia Guimarães e Silva (1996), após o recolhimento dos registros à custódia de uma instituição arquivística, é realizado o tratamento técnico de classificação e de descrição desses objetos, com a representação e o controle intelectual do conteúdo dos documentos nos instrumentos de descrição, os quais serão utilizados na situação de busca por informação por parte do usuário. Assim, “[...] constata-se que não é o documento em si que é oferecido, mas uma representação artificial elaborada pela instituição e sua equipe, sobre o conteúdo do documento" (GUIMARÃES E SILVA, 1996, p. 58).

Guimarães e Silva (1996) considera que, além da custódia de documentos por parte das instituições arquivísticas estar associada à organização e ao armazenamento físico desses objetos com vista à preservação, ela aponta que a descrição arquivística, com a função de representar o conteúdo do acervo na forma de meta-informação (ou informação arquivística), é oferecida como serviço de informação ao usuário do arquivo.

A questão fundamental é que se estabelece um entendimento da descrição arquivística centrada exclusivamente no objeto a ser "descrito", desassociado da própria finalidade disso - o acesso, que envolve a noção de usos que devem ser antevistos para que possam ser viabilizados.

De acordo com Michael Cook (2007), é preciso incorporar a contribuição dos usuários na descrição arquivística. Apenas a adoção de sistemas de computador e os métodos normativos de categorizar a informação descritiva dos acervos arquivísticos não são capazes de contemplar o mundo de usuários em potencial: "Por detrás das normas estão várias suposições culturais que podem precisar ser ajustadas.” (COOK, 2007, p. 130).

O processo de construção das normas de descrição arquivística surge, no final da década de 1980, como uma iniciativa do Conselho Internacional de Arquivos que envolveu a comunidade arquivística internacional. Inicialmente, houve a criação de um grupo de trabalho, posteriormente transformado em Comissão Ad Hoc de Normas de Descrição do CIA. Em 1993, a Comissão 
aprovou a Norma Geral Internacional de Descrição Arquivística - ISAD(G). Esse instrumento normativo estrutura sete áreas de informação para representar e explicar o contexto e o conteúdo de documentos de arquivo, a fim de promover o acesso aos mesmos (FONSECA, 2001).

O surgimento das normas de descrição arquivística representa um movimento de normalização das práticas arquivísticas, que evidencia uma inovação em relação aos manuais (aquela espécie de tradição "manualística"), mas que dá continuidade ao caráter prescritivo do saber arquivístico. Indica uma aposta na normalização das práticas arquivísticas e na perspectiva informacional nos arquivos.

A normalização das práticas arquivísticas é uma tendência atual na Arquivologia, com a valorização dos padrões estabelecidos pelo Conselho Internacional de Arquivos. Para Fonseca (2001), a necessidade das normas seria, além de urgente, um consenso nas instituições arquivísticas brasileiras, que serviriam para equacionar os principais problemas no processamento técnico dos acervos arquivísticos.

Para Claire Sibille (2007), a normalização da descrição arquivística estruturou a ideia de 26 elementos de representação dos arquivos, possibilitando a troca de registros descritivos entre sistemas de informação, mas a descrição como operação intelectual de representar o que se descreve dentro das categorias de informação previstas pelas normas, significa uma ação do profissional em função de demandas de usuários que são antevistas, norteando a análise que vai dar ou não visibilidade a determinados conteúdos nos acervos. O que ampliaria a concepção de descrição envolvendo o acesso seria o nível de consciência do agente em relação à mediação que exerce, escapando ao domínio de padronização estabelecido pelas normas.

Segundo Michael Fox (2007), essa normalização beneficia o acesso intelectual ao acervo por meio dos protocolos que reduzem variações nas formas de apresentação de conteúdos de cada instituição arquivística. As normas significariam uma plataforma para representação do conteúdo dos arquivos, harmonizando a terminologia da descrição aos mapas mentais dos usuários. 
As iniciativas de padronização internacional da descrição arquivística revelam uma tendência em que o conceito de descrição arquivística se confunde com os instrumentos normativos propostos pelo Conselho Internacional de Arquivos. Atualmente, existem normas internacionais para descrever os acervos arquivísticos (ISAD/G: General International Standard Archival Description), os produtores de arquivos (ISAAR/CPF: International Standard Archival Authority Record for Corporate Bodies, Persons and Families), as funções dos produtores de arquivos (ISDF: International Standard for Describing Functions) e as instituições custodiadoras de acervos arquivísticos (ISDIAH: International Standard for Describing Institutions with Archival Holdings).

Os instrumentos de descrição arquivística são entendidos como forma de representar o conteúdo dos documentos e assim, mediar a eventual consulta ao próprio registro. A noção de informação arquivística encontra-se associada à construção de instrumentos de pesquisa que indexam os documentos custodiados por meio da representação de conteúdos, destinados a permitir e orientar a pesquisa pelos usuários (PRET; CORDEIRO, 2015).

Para Barros (2014), a noção de Representação Arquivística seria mais adequada para compreender processos e elaborações que envolvem classificação, descrição, assim como a criação de instrumentos de pesquisa (guias, inventários, catálogos) e sistemas de buscas e bases de dados no contexto dos arquivos. Trata-se da criação de substitutos dos registros documentais por intermédio da representação de seu conteúdo e contexto de origem para usuários dos arquivos.

A ligação entre a elaboração dos instrumentos de pesquisa presentes nos arquivos e o acesso decorre do processo de análise documentária, que consiste em duas etapas básicas: a análise e a síntese dos conteúdos presentes nos documentos. Para Calderon (2003), essa busca por solução dos problemas de acesso e recuperação da informação nos arquivos se traduz na representação da informação, com o objetivo de recuperá-la e disseminá-la.

Tais questões são destinadas, principalmente, às instituições que explicitam ter, entre as suas finalidades, a ampliação do acesso aos acervos que organizam e preservam. Nesta proposta, este quadro de elementos e aspectos do 
acesso aos acervos arquivísticos nas instituições de custódia tem como uma de suas referências o conceito de instrumento de pesquisa. Esses instrumentos refletem o processamento técnico dos documentos custodiados por meio da representação de conteúdos, destinados a permitir e orientar a pesquisa pelos usuários.

Figura 1 - Processamento técnico de acervos arquivísticos

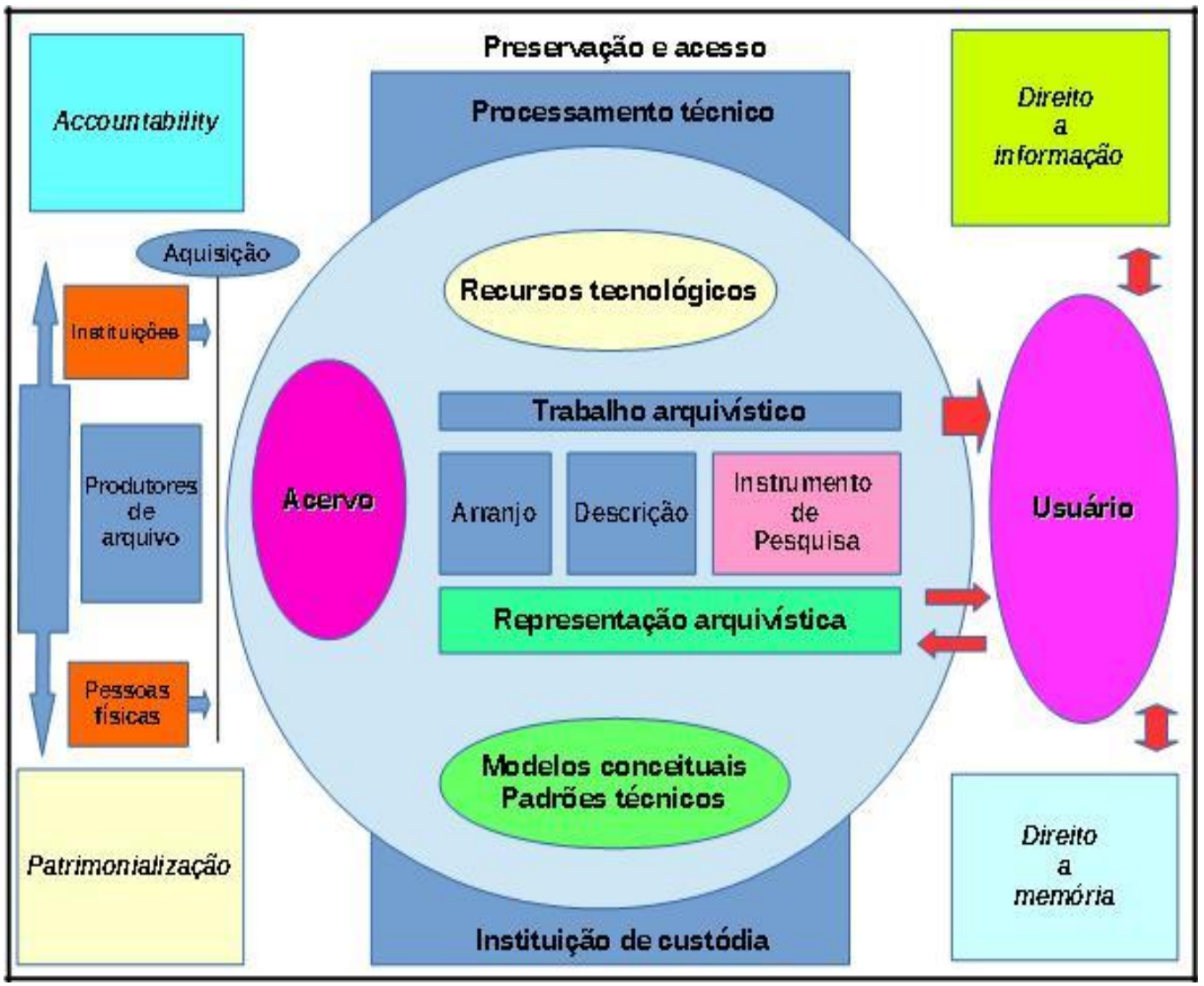

Fonte: Elaborado pelos autores.

É possível ilustrar uma nova perspectiva na divulgação de acervos arquivísticos no Brasil a partir da iniciativa do governo brasileiro com ações que visam ao recenseamento de documentos produzidos por órgãos públicos, bem como por pessoas e entidades de direito privado, em todo o território nacional, de interesse para o tema Lutas Políticas no Brasil (1964-1985). O discurso oficial é que se busca o fortalecimento de uma política pública de valorização do patrimônio histórico documental e de aperfeiçoamento da cidadania e da democracia em nosso país (RIBEIRO, 2015) ${ }^{1}$.

O Centro de Referência das Lutas Políticas no Brasil, também 
denominado Memórias Reveladas, foi criado pela então Ministra da Casa Civil da Presidência da República, Dilma Vana Rousseff, em 2009, sendo implantado no Arquivo Nacional com a articulação entre os entes federados, com vistas ao fortalecimento de uma política de memória do período da ditadura militar.

O banco de dados Memórias Reveladas atualmente está disponível na internet e reúne informações de acervos arquivísticos custodiados por diversas entidades de todo o país, alimentado online pelos parceiros do Centro de Referência das Lutas Políticas no Brasil, consolidando uma anunciada Rede Nacional de Cooperação e Informações Arquivísticas.

Nos dados levantados no banco de dados do portal Memórias Reveladas, em junho de 2018, observou-se que:

a) as descrições do banco de dados são inspiradas na Norma Brasileira de Descrição Arquivística (NOBRADE);

b) existem sete áreas de descrição, divididas em 42 campos;

c) $70 \%$ dos acervos de origem institucional e $30 \%$ de pessoas físicas;

d) $88 \%$ dos acervos estão localizados nos estados de São Paulo, Rio de Janeiro e no Distrito Federal;

e) existem 5,1 milhões de itens e $32 \mathrm{~km}$ de documentos descritos;

f) $62 \%$ dos campos previstos nas normas de descrição arquivística não foram preenchidos.

Para a realização desta pesquisa, foi feita uma leitura das descrições das informações do banco de dados do portal Memórias Reveladas, verificando a qualidade informacional das descrições. Nota-se que $67 \%$ das descrições dispostas no Portal não possuíam informação suficiente para identificar o conteúdo e o contexto dos acervos.

A partir desses dados, observa-se a necessidade de acentuar o comprometimento teórico e metodológico do arquivista com o campo teórico da Organização do Conhecimento, considerando a representação do arquivo na perspectiva da ampliação do acesso aos usuários. É essencial, ainda, não perder de vista os limites discursivos da descrição arquivística por tratar-se de uma representação incapaz de comportar a totalidade do potencial informativo do objeto que pretende descrever. 
Com base nas observações empíricas realizadas no banco de dados do portal Memórias Reveladas, propomos o estabelecimento de mais campos obrigatórios na descrição dos acervos arquivísticos, considerando a pertinente necessidade de se oferecer aos usuários indicadores do contexto de gênese e custódia dos documentos, uma vez que as informações sobre o contexto são elementos capazes de ampliar tanto o significado dos documentos individualmente, quanto de evidenciar a sua autenticidade. Ou seja, verificou-se uma aproximação mais contínua dos estudos arquivísticos com as premissas teóricas da Organização do Conhecimento, de modo a tornar possível o aprimoramento do acesso à informação por um público mais diverso e plural.

Uma das possibilidades de aproximação pauta-se na construção de sistemas de recuperação de informação, de acordo com Kobashi e Francelin (2011), constituindo uma metalinguagem, também chamada linguagem documentária. A função desses recursos de representação está circunscrita ao uso em ambientes de comunicação usuário-sistema de informação e, mesmo sem o poder expressivo da Linguagem Natural, deve comportar estratégias de significação mais precisas com o objetivo último de recuperar informação de conteúdo e contexto do arquivo.

\section{Considerações finais}

Em que pese os recursos tecnológicos já utilizados pelas instituições arquivísticas para a ampliação dos usos e usuários de seus acervos, dois pontos ainda carecem de uma investigação mais aprofundada. Primeiro, constata-se, no Brasil, uma identificação precária entre os arquivos públicos e a maior parte da população. Segundo, nota-se a insuficiência dos instrumentos de pesquisa das entidades custodiadoras de acervos arquivísticos para atingir um público amplo que comumente não visitaria os arquivos. A consequência disso é que os arquivos, conforme apontado por Jardim (1996, 1998, 1999a, 1999b), permanecem distantes da população. Nossa percepção atual é que essa situação não se alterou de forma significativa, apesar de avanços como a legislação sobre os arquivos e o acesso à informação. 
Para isto, torna-se fundamental pensar sobre os instrumentos de pesquisa, para os usos que podem ser feitos dos arquivos, não somente como o uso reservado a atividades do serviço público, mas principalmente como recurso importante para o cidadão na construção de sua identidade e cidadania. Isso significa dizer que se acredita na concretização do direito à informação governamental por parte do cidadão como um caminho de transparência do Estado à sociedade civil, capaz de efetivar a participação política como dimensão básica da cidadania e minimização de desigualdades sociais.

A ampliação da capacidade de atendimento das instituições arquivísticas aos usuários de seus acervos continua sendo um importante desafio, assim como a diversificação deste público, tradicionalmente composto por historiadores. Ainda deve ser feito muito para ampliar a abrangência do acesso aos arquivos por diversos setores da sociedade, como nos relacionamentos com minorias; no modo como elegemos arquivos pessoais como patrimônio; nas questões emergentes sobre os instrumentos de pesquisa disponíveis na internet; nas respostas às questões de direitos humanos e de justiça social.

A perspectiva deve ser a busca por uma rede de arquivos que facilite a pesquisa num mundo cada dia mais conectado. Para atingir essa agenda, as instituições arquivísticas precisam transformar o quadro atual, com práticas mais abrangentes diante de um novo conjunto de usos culturais dos arquivos.

\section{Referências}

ASSMANN, Aleida. Espaços da recordação: formas e transformações da memória cultural. Campinas, SP: UNICAMP, 2011.

BAK, Greg; HILL, Amanda. Deseronto dreams: archives, social networking services, and place. Archivaria, Ottawa, v. 79, p. 1-26, 2015.

BAKHTIN, Mikhail. Marxismo e filosofia da linguagem. São Paulo: Hucitec, 2002.

BARROS, Thiago Henrique Bragato. A representação da informação arquivística: uma análise do discurso teórico e institucional a partir dos contextos espanhol, canadense e brasileiro. 2014. Tese (Doutorado em Ciência da Informação) - Faculdade de Filosofia e Ciências, Universidade Estadual Paulista, Marília, 2014. 
BELKIN, Nicholas J.; ROBERTSON, Stephen E. Information science and the phenomenon of information. Journal of the American Society for Information Science, Washington, v. 27, n. 4, p. 197-204, July/Aug. 1976.

BERGER, P. L.; LUCKMANN, T. A construção social da realidade. Petrópolis: Vozes, 1985.

BRASIL. Ministério da Justiça e Segurança Pública. Memórias reveladas. [S.l.]: Arquivo Nacional, 2019.

CALDERON, Wilmara Rodrigues. Instrumentos de pesquisa nos arquivos públicos permanentes: um estudo sob a ótica da análise documentária. 2003. Dissertação (Mestrado em Ciência da Informação) - Escola de Comunicação e Artes, Universidade de São Paulo, São Paulo, 2003.

CANDAU, Joël. Anthoropologia de la mémoire. Paris: Presses Universitaires de France, 1996.

COOK, Michael. Desenvolvimentos na descrição arquivística: algumas sugestões para o futuro. Acervo, Rio de Janeiro, v. 20, n. 1-2, p.125-132, jan./dez. 2007.

COURTINE, Jean-Jacques. Analyse du discours politique. Langages, Paris, v. 15, n. 62, p. 1-128, 1981.

FONSECA, Vitor Manoel Marques da. A normalização da descrição arquivística: avanços internacionais e a situação do Brasil. Rio de Janeiro: Arquivo Nacional do Brasil, 2001.

DAHLBERG, Ingetraut. Teoria do conceito. Ciência da Informação, Rio de Janeiro, v. 7, n. 2, p. 101-107, 1978.

FOX, Michael. Por que precisamos de normas. Acervo, Rio de Janeiro, v. 20, n. 1-2, p. 23-30, jan./dez. 2007.

GONÇALVES, José Reginaldo Santos. O patrimônio como categoria de pensamento. In: ABREU, Regina; CHAGAS, Mario (org.). Memória e patrimônio: ensaios contemporâneos. Rio de Janeiro: DP\&A, 2003.

HALBWACHS, Maurice. La mémoire collective. Paris: Albin Michel, 1997.

HUYSSEN, Andreas. Seduzidos pela memória: arquitetura, monumentos, mídia. Rio de Janeiro: Aeroplano, 2000.

JAPIASSU, Hilton Ferreira. Interdisciplinaridade e patologia do saber. Rio de Janeiro: Imago, 1976. 
JARDIM, José Maria. A invenção da memória nos arquivos públicos. Ciência da Informação, Brasília, v. 25, n. 2, p. 1-13, 1996.

JARDIM, José Maria. Os arquivos (in)visíveis: a opacidade informacional do Estado brasileiro. 1998. Tese (Doutorado em Ciência da Informação) - Escola de Comunicação, Universidade Federal do Rio de Janeiro, Rio de Janeiro, 1998.

JARDIM, José Maria. A produção de conhecimento arquivístico: perspectivas internacionais e o caso brasileiro (1990-1995). In: JARDIM, José Maria;

FONSECA, Maria Odila (org.). A formação do arquivista no Brasil. Niterói: Eduff, 1999a.

JARDIM, José Maria. Transparência e opacidade do Estado no Brasil: usos e desusos da informação governamental. Niterói: Eduff, 1999b.

KOBASHI, Nair Yumiko; FRANCELIN, Marivalde Moacir. Conceitos, categorias e organização do conhecimento. Informação e Informação, Londrina, v.16 n.3, p.1-24, jan./jun. 2011.

LEÃO, Flávia Carneiro. A representação da informação arquivística permanente: a normalização descritiva e a $\operatorname{ISAD}(\mathrm{G})$. 2006. Dissertação (Mestrado em Ciências da Comunicação) - Escola de Comunicação e Artes, Universidade de São Paulo, São Paulo, 2006.

NAMER, Gerard. Memoire et Societe. Paris: Méridiens Klincksieck, 1987.

NESMITH, Tom. Seeing archives: postmodernism and the changing intellectual place of archives. The American Archivist, Chicago, v. 65, n. 1, p. 24-41, 2002.

OLIVEIRA, Lucia Maria Velloso. Modelagem e status científico da descrição arquivística no campo dos arquivos pessoais. São Paulo: FFLCH, 2010.

ORRICO, Evelyn Goyannes Dill. Binômio lingüística-Ciência da Informação: abordagem teórica para elaboração de metafiltro de recuperação da informação. 2001. Tese (Doutorado em Ciência da Informação) - Escola de Comunicação, Universidade Federal do Rio de Janeiro, Rio de Janeiro, 2001.

PÊCHEUX, Michel. Papel da Memória. In: ACHARD, Pierre et al. Papel da Memória. Campinas, SP: Pontes, 1999.

PRET, Raquel Luise; CORDEIRO, Rosa Inês de Novais. A indexação como ferramenta da gestão de documentos nos arquivos. In: ENCUENTRO IBÉRICO EDICIC, 7., 2015, Madrid. Actas do [...]. Madrid: Universidad Complutense de Madrid, 2015. p. 1-15.

RIBEIRO, Cintia da Silva. A descrição arquivística no Brasil: uma análise do banco de dados do portal Memórias Reveladas. 2015. Trabalho de Conclusão de 
Curso (Bacharelado em Arquivologia) - Centro de Ciências Humanas e Sociais, Universidade Federal do Estado do Rio de Janeiro, Rio de Janeiro, 2015.

SARACEVIC, Tefco. The concept of "relevance" in Information Science: a historical review. In: SARACEVIC, Tefco (ed.). Annual Review of Information Science: introduction to Information Science. New York: Bowker Company, 1970.

SIBILLE, Claire. A descrição arquivística na França, entre normas e práticas. Acervo, Rio de Janeiro, v. 20, n. 1-2, p. 93-112, jan./dez. 2007.

SILVA, Eliezer Pires da; ORRICO, E. G. D. O trabalho da descrição de acervo arquivístico no Brasil. In: DODEBEI, Vera; GUIMARÃES, José Augusto Chaves (org.). Complexidade e organização do conhecimento: desafios do nosso século. Rio de Janeiro: ISKO-Brasil, 2013. v. 1, p. 211-216.

SILVA, Júnia Guimarães e. Socialização da informação arquivística: a viabilidade de enfoque participativo na transferência da informação. 1996. Dissertação (Mestrado em Ciência da Informação) - Escola de Comunicação, Universidade Federal do Rio de Janeiro, Rio de Janeiro, 1996.

TODOROV, Tzvetan. Les abus de la mémoire. Paris: Arléa, 1998.

WERSIG, Gernot. Information Science: the study of postmodern knowledge usage. Infomation Processing \& Manageent, Amsterdam, v. 29, n. 2, p.229239, 1993.

\title{
Scientific dissemination in Brazilian archives: archival information representation for the construction of memory and identity
}

\begin{abstract}
Promoting the dissemination of archival collections to a wide audience is a stimulating task because traditionally this public does not visit the archives. The task is also stimulating because it puts into practice the transmission of technical-scientific productions to society, which, by allowing access to these collections, have a fundamental role as a resource for the construction of social memory, considering the possibility of making visible a documentary production still restricted to a few, allowing the archives to fulfill its social and cultural function. The assumption that it is a social function of the archives to increase the use of its collections and the number of its users and thus to enable the right to information is what guides this study on the conditions of access to the archive documents by the population. This way, the archive allows the accomplishment of full citizenship. The dissemination allows
\end{abstract}


that these institutions reach an bigger public to use their collections, increasing the number of its users. The purpose of this study is to analyze the obstacles for this expansion of access to documents kept in the archives, analyzing the procedures used by institutions that announce such purpose for the collections they organize and preserve. This research not only broadens the knowledge about archives as an information resource for the citizens, but it mainly provides knowledge production on a fundamental theme for the emergence of new discussions in the academic space involving several social actors: the representation of archival knowledge for the lay population.

Keywords: Scientific dissemination. Archives. Memory.

Recebido: $25 / 07 / 2018$

Aceito: $14 / 11 / 2018$

\footnotetext{
${ }^{1}$ Centro de Referência das Lutas Políticas no Brasil, denominado Memórias Reveladas, foi institucionalizado em 2009 pela Casa Civil da Presidência da República e implantado no Arquivo Nacional com a finalidade de reunir informações sobre os fatos da história política recente do País (BRASIL, 2019).
} 